\title{
Twins and Causal Inference: Leveraging Nature's Experiment
}

\author{
Tom A. McAdams, ${ }^{1,2}$ Fruhling V. Rijsdijk, ${ }^{1}$ Helena M.S. Zavos, ${ }^{3}$ and Jean-Baptiste Pingault ${ }^{1,4}$ \\ ${ }^{1}$ Social, Genetic and Developmental Psychiatry Centre, Institute of Psychiatry, Psychology and Neuroscience, \\ King's College London, London SE5 8AF, United Kingdom \\ ${ }^{2}$ Promenta Research Centre, University of Oslo, Oslo 0373, Norway \\ ${ }^{3}$ Department of Psychology, Institute of Psychiatry, Psychology \& Neuroscience, King's College London, London \\ SE5 8AF, United Kingdom \\ ${ }^{4}$ Clinical, Educational and Health Psychology, Division of Psychology and Language Sciences, University \\ College London, London WC1E 6BT, United Kingdom \\ Correspondence: tom.mcadams@kcl.ac.uk
}

In this review, we discuss how samples comprising monozygotic and dizygotic twin pairs can be used for the purpose of strengthening causal inference by controlling for shared influences on exposure and outcome. We begin by briefly introducing how twin data can be used to inform the biometric decomposition of population variance into genetic, shared environmental, and nonshared environmental influences. We then discuss how extensions to this model can be used to explore whether associations between exposure and outcome survive correction for shared etiology (common causes). We review several analytical approaches that can be applied to twin data for this purpose. These include multivariate structural equation models, cotwin control methods, direction of causation models (cross-sectional and longitudinal), and extended family designs used to assess intergenerational associations. We conclude by highlighting some of the limitations and considerations that researchers should be aware of when using twin data for the purposes of interrogating causal hypotheses.

$T^{r}$ win studies are most often associated with the estimation of heritability and understanding the extent to which correlated traits share common genetic causes. This focus on genetics often means that the role of twin studies in understanding nongenetic influences on human behavior is overlooked. However, twin studies have demonstrated that around half of the variance in human traits is attributable to nongenetic influences (Polderman et al. 2015). Furthermore, as well as partitioning variance into genetic and environmental influences, it is possible to use twin studies to ask whether associations between exposure and outcome remain after accounting for the confounding effects of shared etiology (common causes). In this manner, twin studies can be thought of as quasi-experimental. By controlling for common causes, twin studies can test what have been referred to as "quasi-causal hypotheses" (Turkheimer and Harden 2014). The use of phrases like "quasi-causality" and "causal inference" (as opposed to straightforward "causality") highlights that twin studies (like other ep-

Editors: George Davey Smith, Rebecca Richmond, and Jean-Baptiste Pingault

Additional Perspectives on Combining Human Genetics and Causal Inference to Understand Human Disease and Development available at www.perspectivesinmedicine.org

Copyright (C 2021 Cold Spring Harbor Laboratory Press; all rights reserved; doi: 10.1101/cshperspect.a039552

Cite this article as Cold Spring Harb Perspect Med 2021;11:a039552 
T.A. McAdams et al.

idemiological approaches) cannot typically demonstrate causality between two variablesthey cannot prove that $\mathrm{X}$ (the exposure) causes $\mathrm{Y}$ (the outcome). They can, however, show that $\mathrm{X}$ does (or does not) continue to predict $\mathrm{Y}$ after controlling for shared etiology, thereby strengthening the ability of researchers to make causal inferences. This is the primary focus of our review.

\section{THE TWIN MODEL}

Before discussing the use of twin studies in causal inference, it is necessary first to briefly introduce the logic underlying twin studies. The classical twin design typically decomposes phenotypic variance $(\mathrm{Vp})$ into three components: additive genetic (A), shared environment (C), and nonshared environment (E) influences. Additive genetic influences (A) refer to effects of alleles or loci which act in an additive manner (two copies of a risk allele at the same locus confer twice the risk of one copy). ${ }^{5}$ Shared environment $(\mathrm{C})$ refers to environmental effects that make members of the same family similar to one another. In twin studies, the shared environment is typically defined as environmental effects that make twins similar to one another regardless of zygosity. ${ }^{6}$ Because twins share few-

\footnotetext{
${ }^{5}$ It is possible to model dominant genetic effects in twin models (typically denoted by a D), where effects of risk alleles are modeled as multiplicative rather than additive. However, a typical twin dataset only provides enough information (degrees of freedom) to decompose variance into three components, so researchers need to choose between an ACE or ADE model. Covariance patterns inform this choice: If MZ correlations are more than twice the size of $\mathrm{DZ}$ correlations, then an ADE model is appropriate. If $\mathrm{DZ}$ correlations are more than half the size of MZ correlations, then an ACE model is appropriate. ACE models tend to be fitted more often than ADE models, but all concepts discussed in this paper apply to both. Some extended family designs/datasets allow for ACDE models to be fitted.

${ }^{6}$ This constitutes the equal environments assumption (EEA): the assumption that environmental influences that operate on a trait are shared equally within $\mathrm{MZ}$ and $\mathrm{DZ}$ twin pairs. If environmental influences that make twins alike are more similar for MZ pairs than DZ pairs-for reasons besides MZ pairs being more genetically alike-then twin model estimates will be biased. Studies of misclassified twins (MZ pairs labeled as DZs and vice versa) provide a powerful test of the EEA and lend support to the validity of this assumption (Kendler et al. 1993; Conley et al. 2013).
}

er environmental experiences as they age, the effect of the shared environment diminishes with age for most traits (e.g., Haworth et al. 2010). In extended family studies, it is possible to vary the definition of shared environmental effects to include, for example, siblings or entire nuclear families. The nonshared environment (E) refers to effects that make members of the same family different from one another. While typically referred to as the nonshared environment, the E component in a twin model comprises the residual variance in a trait remaining after genetic and shared environmental effects are considered. As such, E will comprise error variance and the effects of random nonshared biological events (Smith 2011; Tikhodeyev and Shcherbakova 2019) as well as true nonshared environmental influences.

In Figure 1, we show the classical univariate twin model used to decompose variance in a trait into A, C, and E components. The method involves comparing the degree of resemblance between pairs of monozygotic (MZ) twins and dizygotic (DZ) twins. Resemblance within MZ twin pairs $\left(r_{M Z}\right)$ is attributable to twins sharing all of their genes and a shared environment $\left(r_{M Z}\right.$ $=\mathrm{A}+\mathrm{C})$. Resemblance within $\mathrm{DZ}$ pairs $\left(\mathrm{r}_{\mathrm{DZ}}\right)$ is expressed as $r_{D Z}=1 / 2(A)+C$; as $D Z$ twins share only half their segregating genes on average, but they are assumed to share the shared environment to the same extent as MZ pairs (100\%).

In the twin design, heritability is calculated as twice the difference between $\mathrm{MZ}$ and $\mathrm{DZ}$ correlations: $A=2\left(r_{M Z}-r_{D Z}\right)$. Shared environments can be estimated as the difference between the $\mathrm{MZ}$ correlation and the heritability: $\mathrm{C}=\mathrm{r}_{\mathrm{MZ}}-\mathrm{A}$. As nonshared environment is the only influence that acts to make MZ twins different from one another, it can be calculated as the total $\mathrm{Vp}$ (often standardized to 1 for ease of interpretation) minus the MZ correlation: $\mathrm{E}=\mathrm{Vp}-\mathrm{r}_{\mathrm{MZ}}$.

\section{UNDERSTANDING CONFOUNDING USING TWIN MODELS}

In their "Top 10 replicated findings from behavioral genetics," two of the most replicated findings highlighted by Plomin et al. (2016) are of 


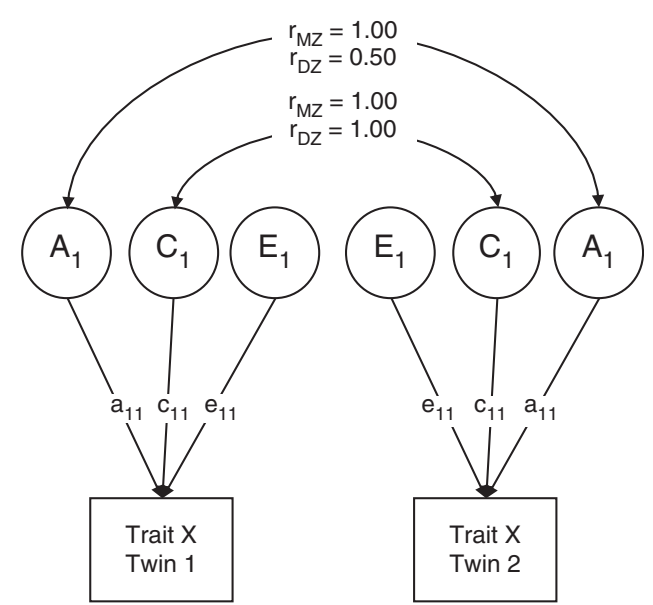

Figure 1. Path diagram of the univariate twin model. All of our path diagrams follow standard structural equation modeling conventions, whereby measured variables are represented with squares and latent variables are represented with circles. Although not included in the path diagram, the variances of all latent variables are fixed to unity. $\left(a_{11}\right)$ Additive genetic effects on phenotype, $\left(c_{11}\right)$ shared environmental effects on phenotype, $\left(e_{11}\right)$ nonshared environmental effects on phenotype, $\left(A_{1}\right)$ additive genetic variance component, $\left(\mathrm{C}_{1}\right)$ shared environmental variance component, $\left(\mathrm{E}_{1}\right)$ nonshared environmental variance component. In the classical twin design, the predicted variances of each trait $\left(\mathrm{a}_{11}{ }^{2}+\mathrm{c}_{11}{ }^{2}+\mathrm{e}_{11}{ }^{2}\right)$ and the predictions for the covariances $\left(\mathrm{a}_{11}{ }^{2}+\mathrm{c}_{11}{ }^{2}\right.$ for $\mathrm{MZ}$ and $0.5 \mathrm{a}_{11}{ }^{2}+\mathrm{c}_{11}{ }^{2}$ for DZ pairs) are fitted to the observed variances and covariances to obtain the most likely estimates for the $\mathrm{A}, \mathrm{C}$, and $\mathrm{E}$ effects.

crucial importance to researchers interested in drawing causal inference from associations among variables in nonexperimental studies:

\section{Phenotypic Correlations among Traits Often Show Substantial Genetic Influence}

In other words, when two traits correlate, it is often because they share common genetic causes. This can be attributed to the joint influences of pleiotropy (whereby genetic variants associate with multiple traits) and polygenicity (whereby traits are associated with many genetic variants). The possibility of shared genetic influences highlights a major reason why associations among traits should not be interpreted as indicative of causal influences of one trait on another. Importantly, this applies to prospective as well as cross-sectional associations. That is, we cannot assume that genetic factors that influence trait $X$ (exposure) at time point 1 will not influence trait $\mathrm{Y}$ (outcome) at time point 2 , thus explaining some or all of their covariance. For example, anxiety in childhood is predictive of later depression, and while this may be because anxiety leads to depression, it is also possible that genetic influences underlying childhood anxiety may manifest as depression later in life (Rice et al. 2004).

It is worth considering here that the above discussion assumes horizontal pleiotropy, whereby genetic variants influence both $\mathrm{X}$ and $\mathrm{Y}$ and induce or inflate covariance between them. However, genetic covariance between $\mathrm{X}$ and $\mathrm{Y}$ can also come about through vertical pleiotropy, whereby $\mathrm{X}$ causally influences $\mathrm{Y}$, resulting in genetic variants associated with $\mathrm{X}$ becoming associated with Y. Horizontal pleiotropy constitutes a source of confounding on the association between $\mathrm{X}$ and $\mathrm{Y}$, whereas vertical pleiotropy does not. In practice, it is difficult to distinguish these two possibilities, and most twin studies aimed at testing quasi-causal hypotheses do not attempt to do so, instead accounting for genetic covariance among traits and evaluating whether associations persist. Where genetic covariance is attributable to vertical pleiotropy, associations may therefore be overcorrected. However, provided that genetic factors do not explain all of the variance in $\mathrm{X}$, then controlling for vertical pleiotropy as though it were horizontal pleiotropy will not reduce the association between $\mathrm{X}$ and $\mathrm{Y}$ to zero, because the residual variance in $\mathrm{X}$ will still predict Y. Given that no phenotypes are $100 \%$ heritable (or indeed 100\% familial [Polderman et al. 2015; Plomin et al. 2016]), then where a significant causal effect of $\mathrm{X}$ on $\mathrm{Y}$ exists, their association should not reduce to zero when controlling for potential familial confounds using twin methods. Implicit here is the expectation that the residual covariance will be large enough to be detected. A caveat to this is that where heritability of $\mathrm{X}$ is very high, then power to detect a residual association after accounting for genetic correlation may be limited. 
T.A. McAdams et al.

\section{Most Measures of Putative "Environmental Exposures" Show Genetic Influence}

Measures that index experiences and environments such as life events, social support, and exposure to toxins (i.e., variables commonly conceptualized as environmental exposures that may influence human traits) correlate with (and may be under the influence of) genetic factors (Jaffee and Price 2007; Kendler and Baker 2007). This is referred to as gene-environment correlation (rGE) and has important consequences for researchers interested in drawing causal inferences from associations between putative environmental exposures and outcomes. That is, if an environmental exposure is predictive of a particular outcome, but both outcome and exposure are heritable, then it is possible that the association is partially or entirely accounted for by shared genetic influences. Again, the joint influences of pleiotropy and polygenicity mean that genetic correlations between putative environmental exposures and outcomes should be considered likely.

Three forms of rGE are typically distinguished from one another and give some insight into why putative environmental variables may be heritable: (1) Passive rGE occurs when people are born into an environment that correlates with their genotype. For example, most children are reared by their biological relatives, so many elements of their environment will be correlated with their genotype. Recently, this concept has been reintroduced into the literature in discussions surrounding "genetic nurture" and "dynastic effects" - the environmentally mediated genetic effects of biological relatives (Fletcher 2011; Fletcher and Lehrer 2011; Eaves et al. 2014; Kong et al. 2018; Young et al. 2019; Ystrom and Eilertsen 2019). See Cheesman et al. (2020) and Hwang et al. (2020) for more discussion on this. (2) Evocative rGE occurs when an individual's genetically influenced traits evoke a particular response from the environment, leading to a correlation between genotype and environment. For example, a child may be genetically predisposed toward characteristics that evoke negative responses from other people. In this manner, evocative rGE can lead to measures of parental negativity correlating with the child's genotype, and thus being heritable (e.g., Neiderhiser et al. 2004, 2007b). (3) Active rGE occurs when an individual seeks out an environment that matches their genotype. For example, an adolescent may actively seek a peer group composed of adolescents similar to them. In this manner, active rGE could lead to a measure of peer group deviancy being heritable (Kendler et al. 2007).

Crucially, any of these forms of rGE can lead to an association between a putative environmental exposure and an outcome without the environmental exposure causally influencing the outcome. Similarly, when an environmental exposure does have an effect, rGE may inflate the magnitude of the association between environment and outcome. To extend the three examples above: (1) Passive rGE can inflate associations between parent and child traits. For example, exposure to maternal depression during childhood is predictive of child emotional and behavioral problems, but this association is inflated by genetic overlap between parent and child traits (Gjerde et al. 2019). (2) Evocative rGE can lead to associations between adolescent behavioral problems and parental negativity, even if parental negativity does not necessarily cause adolescent behavioral problems (McAdams et al. 2013). (3) Active rGE may inflate the association between peer group deviancy and adolescent delinquency (Kendler et al. 2008).

Clearly then, accounting for rGE is important where researchers want to know the extent to which a putative environmental risk factor may have a direct effect on an outcome of interest. That said, it is worth noting that while rGE is often conceptualized and treated as a cause of confounding between exposure and outcome, there are situations in which rGE can provide a tool through which the effects of environmental exposures can be assessed. For example, where variants are causally predictive of exposure, they can be used as instrumental variables to assess links between exposure and outcome (Gage et al. 2016; Millwood et al. 2019; Richmond 2020). 


\section{MULTIVARIATE TWIN MODELS AND CAUSAL INFERENCE}

A major challenge when testing associations between exposures and outcome in nonexperimental research settings is the effective identification and measurement of confounding variables. Confounders may be unknown and when not accounted for they will have the effect of biasing estimates of associations. Furthermore, it is likely that most associations could be confounded by many shared influences. For example, the consumption of alcohol has been shown to correlate with a range of health outcomes in positive and negative directions. Most of these associations could potentially be confounded by a wide range of socioeconomic, cultural, dietary, and health-behavior-related influences. Identifying and controlling for all of these confounders would be a huge (and essentially impossible) challenge, and including them all in a regression analysis would reduce the power of that analysis to identify any remaining effects. Even if all relevant confounders could be included, errors in the measurement of these confounders could still vitiate the ability to statistically control for them, and thus lead to biased effect estimates. Twin data can be used to circumvent many of these issues by controlling for genetic and shared environmental influences common to exposure and outcome.
In this manner, multivariate twin models can control for common causes without the need to identify and measure specific confounders.

It is beyond the scope of this paper to review all multivariate models to date applied to twin data but, suffice it to say that such data can be used to explore etiological overlap among traits, and between exposures and outcomes, in many ways. For the purpose of this review, we focus on models that are (or can be) used in attempts to draw causal inference. We do not claim to cover all such models, but the underlying logic that we discuss will typically extend to twin models we do not cover.

Where univariate twin models are used to decompose the variance of a trait into genetic and environmental influences, multivariate models are concerned with decomposing covariance among traits in a similar manner. Figure 2 shows how to specify a twin model such that the covariance between two variables, $\mathrm{X}$ and $\mathrm{Y}$, is decomposed into $\mathrm{A}, \mathrm{C}$, and $\mathrm{E}$ components in the manner of a Cholesky decomposition.

The Cholesky decomposition disaggregates the variance in trait $\mathrm{X}$ into genetic $\left(\mathrm{A}_{1}\right)$, shared environmental $\left(\mathrm{C}_{1}\right)$, and nonshared environmental $\left(E_{1}\right)$ factors, which have their effects on $\mathrm{X}$ via paths $\mathrm{a}_{11}, \mathrm{c}_{11}$, and $\mathrm{e}_{11}$. These factors are also able to account for variance in trait $\mathrm{Y}$ via paths $\mathrm{a}_{21}, \mathrm{c}_{21}$, and $\mathrm{e}_{21}$. It is these paths that account for the covariance between trait X and Y. By comparing $\mathrm{MZ}$ and DZ cross-twin, cross-trait corre-

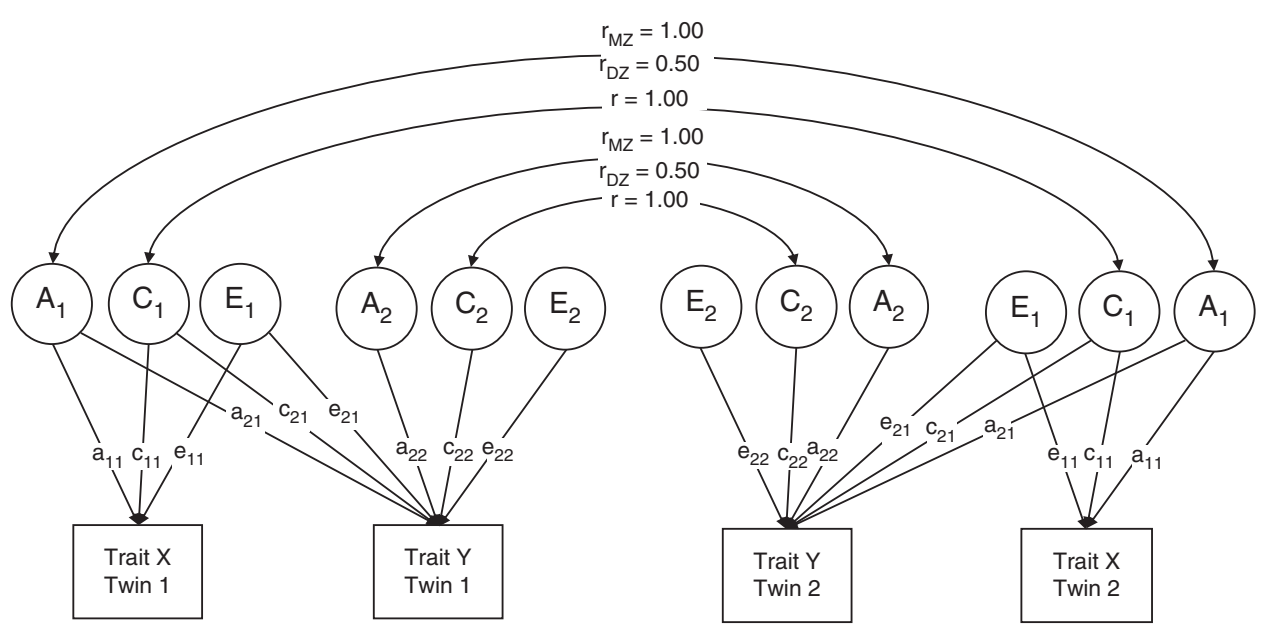

Figure 2. Cholesky decomposition twin model. 
T.A. McAdams et al.

Table 1. Variance-covariance specification for a bivariate Cholesky decomposition

\begin{tabular}{|c|c|c|c|c|}
\hline & Trait X Twin 1 & Trait $Y$ Twin 1 & Trait $X$ Twin 2 & Trait $Y$ Twin 2 \\
\hline Trait X Twin 1 & $\mathrm{a}_{11}^{2}+\mathrm{c}_{11}^{2}+\mathrm{e}_{11}^{2}$ & $\begin{array}{c}\mathrm{a}_{11}{ }^{*} \mathrm{a}_{21}+\mathrm{c}_{11}{ }^{*} \mathrm{c}_{21}+ \\
\mathrm{e}_{11}{ }^{*} \mathrm{e}_{22}\end{array}$ & $.5^{*} \mathrm{a}_{11}^{2}+\mathrm{c}_{11}^{2}$ & $a_{11}^{*} \cdot 5^{*} a_{21}+c_{11}^{*} c_{21}$ \\
\hline Trait Y Twin 1 & $\begin{array}{c}\mathrm{a}_{11}{ }^{*} \mathrm{a}_{21}+\mathrm{c}_{11}{ }^{*} \mathrm{c}_{21}+ \\
\mathrm{e}_{11} \mathrm{e}_{22}\end{array}$ & $\begin{array}{l}\mathrm{a}_{21}{ }^{2}+\mathrm{c}_{21}{ }^{2}+\mathrm{e}_{21}{ }^{2} \\
+\mathrm{a}_{22}{ }^{2}+\mathrm{c}_{22}{ }^{2}+ \\
\mathrm{e}_{22}{ }^{2}\end{array}$ & $a_{11}^{*} \cdot 5^{*} a_{21}+c_{11}{ }^{*} c_{21}$ & $\begin{array}{c}.5^{*} \mathrm{a}_{21}{ }^{2}+\mathrm{c}_{21}{ }^{2}+ \\
.5^{*} \mathrm{a}_{22}{ }^{2}+\mathrm{c}_{22}{ }^{2}\end{array}$ \\
\hline Trait X Twin 2 & $\mathrm{a}_{11}^{2}+\mathrm{c}_{11}^{2}$ & $a_{11}^{*} a_{21}+c_{11}^{*} c_{21}$ & $\mathrm{a}_{11}^{2}+\mathrm{c}_{11}^{2}+\mathrm{e}_{11}^{2}$ & $\begin{array}{c}\mathrm{a}_{11}{ }^{*} \mathrm{a}_{21}+\mathrm{c}_{11}{ }^{*} \mathrm{c}_{21}+ \\
\mathrm{e}_{11}{ }^{*} \mathrm{e}_{22}\end{array}$ \\
\hline Trait Y Twin 2 & $\mathrm{a}_{11}{ }^{*} \mathrm{a}_{21}+\mathrm{c}_{11}{ }^{*} \mathrm{c}_{21}$ & $\begin{array}{c}\mathrm{a}_{21}{ }^{2}+\mathrm{c}_{21}{ }^{2}+\mathrm{a}_{22}{ }^{2}+ \\
\mathrm{c}_{22}{ }^{2}\end{array}$ & $\begin{array}{c}\mathrm{a}_{11}{ }^{*} \mathrm{a}_{21}+\mathrm{c}_{11}{ }^{*} \mathrm{c}_{21}+ \\
\mathrm{e}_{11}{ }^{*} \mathrm{e}_{22}\end{array}$ & $\begin{array}{c}\mathrm{a}_{21}{ }^{2}+\mathrm{c}_{21}{ }^{2}+\mathrm{e}_{21}{ }^{2}+ \\
\mathrm{a}_{22}{ }^{2}+\mathrm{c}_{22}{ }^{2}+\mathrm{e}_{22}{ }^{2}\end{array}$ \\
\hline
\end{tabular}

Variances are highlighted in pale blue with black outlines on the diagonal. MZ twin covariances are given below the diagonal and DZ twin covariances are given above the diagonal. Within-twin, cross-trait covariances are highlighted in dark blue. Crosstwin, within-trait covariances are highlighted in pale green. These can be used to decompose variances in X and Y. Cross-twin, cross-trait covariances are highlighted in darker green. These are used to decompose covariance between $\mathrm{X}$ and $\mathrm{Y}$. Note that $\mathrm{e}$ paths are never involved in covariance between twins, only within.

lations (e.g., correlations between trait $\mathrm{X}$ in twin 1 and trait $\mathrm{Y}$ in twin 2), it is possible to decompose the covariance among traits. The residual variance in trait $\mathrm{Y}$ (that is not accounted for by $A_{1}, C_{1}$, and $E_{1}$ ) is decomposed into $A_{2}, C_{2}$, and $\mathrm{E}_{2}$ factors. In Table 1, we show this with a variance-covariance matrix that details how the Cholesky decomposition is specified.

In Figure 3, we demonstrate how the decomposition of covariance among traits can be used to assess whether an association remains and/or is attenuated after accounting for the effects of genetic and shared environmental influences common to both traits. Figure $3 i$ shows a standard linear regression of Y (the outcome or dependent variable) on $\mathrm{X}$ (the exposure or independent variable). This model assumes a causal relationship running from $\mathrm{X}$ to $\mathrm{Y}$ via $\mathrm{B}_{\mathrm{yx}}$. However, this relationship may be confounded by a common causal variable. In Figure 3ii, we show how such a potential confounding variable may operate, and how to model this possibility wherein both $\mathrm{X}$ and $\mathrm{Y}$ are regressed on a potential confounding variable, $\mathrm{Z}$. In this model $\mathrm{B}_{\mathrm{yx}}$, is the effect of $\mathrm{X}$ on $\mathrm{Y}$ after controlling for the confounding effects of $Z^{7}$ In Figure 3iii, we

\footnotetext{
${ }^{7}$ Note that simply regressing $\mathrm{Y}$ on both $\mathrm{X}$ and $\mathrm{Z}$ would have the same effect- $B_{\mathrm{yx}}$ would be corrected for the confounding effects of $Z$. This is the approach most often taken in a linear regression framework.
}

show the partial path diagram for the previously introduced bivariate Cholesky decomposition (for a single individual; in Fig. 2, we show how the same model is specified for twin pairs). We have rearranged the model slightly to highlight similarities to the model in Figure 3ii and to demonstrate how it can be used to control for latent genetic and environmental confounders without the need to identify and measure them. Here, the covariance structure of the data combined with the logic of the twin model enables the decomposition of covariance into $\mathrm{A}, \mathrm{C}$, and E components. In this model, $\mathrm{A}_{1}$ correlates between members of a twin pair (1.00 for $\mathrm{MZ}$ twins and 0.50 for $\mathrm{DZs}$ ) and indexes genetic influences on $\mathrm{X}$ and on correlations between $\mathrm{X}$ and $Y$ (within and between twins, as specified in Fig. 2 and Table 1). In this manner, $A_{1}$ accounts for the confounding effects of common genetic influences affecting both $\mathrm{X}$ (the exposure) and $\mathrm{Y}$ (the outcome). $\mathrm{C}_{1}$ is perfectly correlated between twins of both zygosities and indexes shared environmental influences on $\mathrm{X}$ and on correlations between $\mathrm{X}$ and $\mathrm{Y}$ (within and between twins). As such, $\mathrm{C}_{1}$ accounts for familial environmental influences that may confound the association between $\mathrm{X}$ and $\mathrm{Y}$. $\mathrm{E}_{1}$ does not correlate between twins so only indexes the within-person correlation between $\mathrm{X}$ and $\mathrm{Y}$ after accounting for the genetic and environmental influences that make members of a twin pair 
Twins and Causal Inference
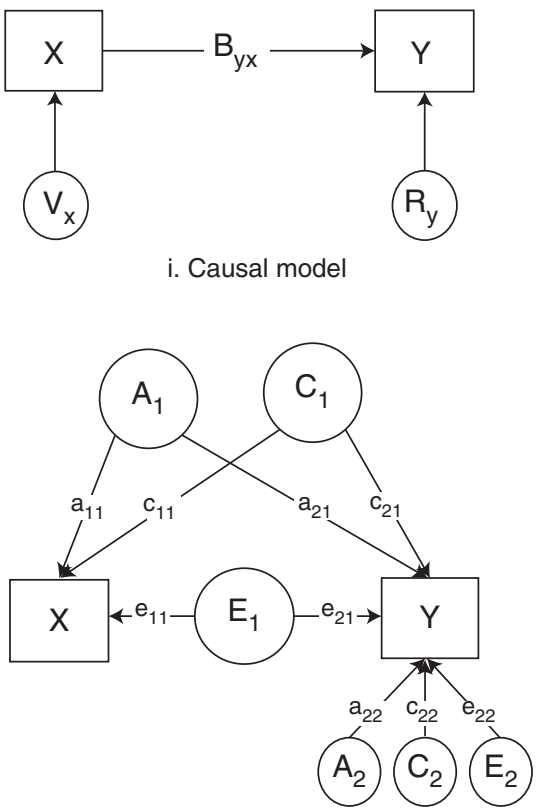

iii. Cholesky decomposition twin model

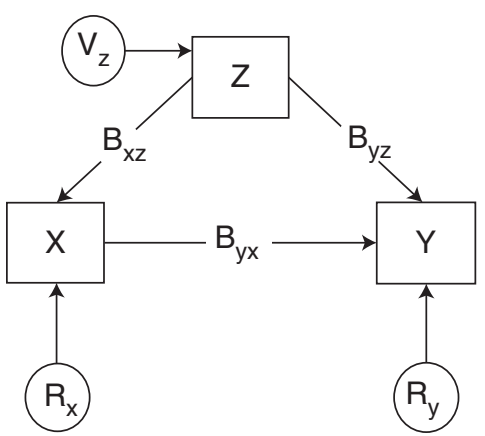

ii. Causal model with confounder

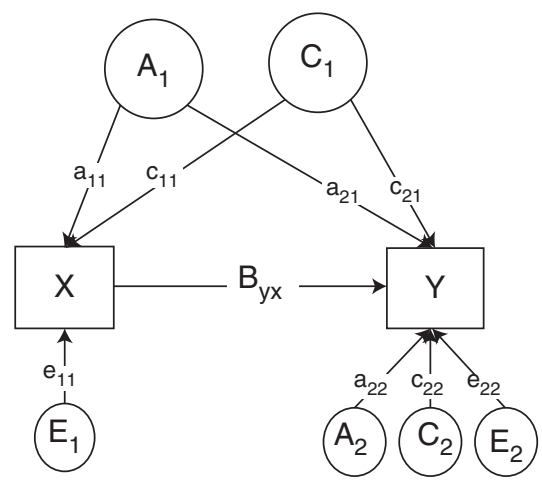

iv. Modeling causality in a twin model

Figure 3. Modeling causality. In the above models, $\mathrm{B}_{\mathrm{yx}}$ is the causal effect of $\mathrm{X}$ on $\mathrm{Y}$. In model $\mathrm{i}, \mathrm{V}_{\mathrm{x}}$ denotes the variance of $X$, and $R_{y}$ denotes the residual variance of $Y$ (the variance of $Y$ remaining after regressing out the effects of $X)$. In model ii, $V_{z}$ denotes the variance of $Z$, and $R_{x}$ and $R_{y}$ denote the residual variances of $X$ and $Y$ (variance remaining after regressing out the effect of $\mathrm{Z}$ ( on $\mathrm{X}$ ) and $\mathrm{Z}$ and $\mathrm{X}$ (on $\mathrm{Y}$ )). Twin models shown are partial path diagrams for a single individual. All latent factors have a variance of 1 (not shown).

similar to one another. In this manner, $\mathrm{A}_{1}$ and $\mathrm{C}_{1}$ account for latent genetic and shared environmental confounders in the same way that $\mathrm{Z}$ accounts for measured confounders. The advantage in using twin data is that researchers do not have to identify all of the potential confounders that might account for or inflate the association between $\mathrm{X}$ and $\mathrm{Y}$. By using twin data, all potential confounders shared by members of a twin pair (genetic and shared environmental influences) can be accounted for.

In Figure 3iv, we show how twin data can be used to create a model very close to that of $3 \mathrm{ii}$. Arguably, given that $\mathrm{B}_{\mathrm{yx}}$ is not recovered from a Cholesky decomposition, the model in Figure 3iv provides the "cleanest" test when using twin data to assess whether the association be- tween $\mathrm{X}$ and $\mathrm{Y}$ survives correction for common confounders, although Cholesky decompositions are more often applied in the literature. Importantly though, the models shown in Figure 3iii and 3iv will result in the same conclusions being drawn if fitted to the same data. That is, if $\mathrm{B}_{\mathrm{yx}}$ explains covariance between $\mathrm{X}$ and $\mathrm{Y}$ in model 3iv, then the path running $\mathrm{e}_{11}{ }^{*} \mathrm{e}_{12}$ in model 3iii will also do so. Either of these paths can be used to evaluate whether the association between X and Y persists after accounting for common genetic and shared environmental influences (Turkheimer and Harden 2014). It should be noted, however, that such a residual association does not on its own constitute evidence of causality for at least two reasons. First, nonshared environmental confounders are un- 
T.A. McAdams et al.

accounted for and could still explain some or all of the associations between $\mathrm{X}$ and $\mathrm{Y}$. It is of course possible to further control for additional observed nonshared environmental confounders (e.g., differences in birth weight or baseline levels of the outcome). However, challenges encountered in identifying and measuring specific nonshared environmental influences may make this a challenging task (Neiderhiser et al. 2007a). Second, reverse causation can bias estimates resulting from these models, that is, the estimate of the effect of $\mathrm{X}$ on $\mathrm{Y}$ can (partially) reflect the effect of $\mathrm{Y}$ on X. Longitudinal models with clear temporality (e.g., birth weight to attention-deficit/hyperactivity disorder [ADHD] symptoms) or repeated measures of the exposure and the outcome can mitigate but not always fully account for reverse causation.

\section{THE COTWIN CONTROL DESIGN}

The application of structural equation models to decompose covariance among variables is one technique through which researchers can use multivariate twin data to ask the question "does the association between $\mathrm{X}$ and $\mathrm{Y}$ persist after accounting for genetic and shared environmental confounds?" Another method involves strengthening causal inference by using one twin in a pair as a direct matched control for the other. This approach is known as the "cotwin control design" in the field of behavioral genetics and as one implementation of the "fixed effects" approach in econometrics. Whereas the biometrical decomposition of variance discussed above is most often used to dissect the etiological architecture of phenotypes, the main purpose of the cotwin design is causal inference.

The cotwin control design is best understood within the counterfactual framework for causal inference (Lynch 2020). In the (theoretical) counterfactual situation, a given individual receives a treatment (or is exposed to a risk factor value) and, at the same time, the same individual does not receive the treatment. In this ideal situation, the treated individual is literally the same as the control individual, the only difference being the treatment. It thus becomes possible to estimate the causal effect of that treatment, even at the individual level. Naturally, in real life, the same individual cannot at the same time receive and not receive a treatment, so strict causal inference is impossible. However, all causal inference designs can be conceived as aiming to approximate this ideal counterfactual situation (Pingault et al. 2018). One way to approximate this situation is to find the best match possible. This is when twins, and in particular MZ twins, come into play. Indeed, an exposed twin shares all of their genetic material and, by definition, their shared environment with the nonexposed cotwin. At a basic level, the cotwin design involves comparing outcomes between the exposed and nonexposed twin, and thus controlling for genetic and shared environmental influences. If the risk factor (e.g., smoking) causes the outcome (e.g., lung cancer), we should expect that on average smoking twins will have a higher incidence of lung cancer than their nonsmoking cotwins. If there was no difference in the incidence of lung cancer in the smoking versus nonsmoking twin, then this would suggest the relationship between the risk factor and the outcome is noncausal and due to genetic or shared environmental confounding.

The cotwin control design is often referred to as the "discordant twin design" when the exposure is binary, and the "twin differences design" when the exposure is continuous. A comprehensive review of regression models used to fit the cotwin design can be found in Carlin et al. (2005). For continuous exposure and outcome, twin differences in the exposure and the outcome are first computed. The causal effect is estimated by a simple regression without intercept of the twin differences in the outcome on the twin differences in the exposure. A more complex multilevel model can be fitted, modeling both the within-family estimates and the between-family estimates. The within-family estimates will give exactly the same estimates of the causal effect as the aforementioned simpler approach. This type of model must allow for both an intraclass correlation (the within-twins correlation), which affects the estimate, and robust standard errors. The phenotypic relationship between the exposure and the outcome is a weighted mean of the within- and between-fam- 
ily estimates. They can be fitted in a variety of statistical frameworks that provide very similar estimates and confidence intervals, including mixed models, generalized estimating equations, and structural equation modeling.

The cotwin control design has been widely used for causal inference, confirming for example the causal link between smoking and lung cancer (Hjelmborg et al. 2017), demonstrating the impact of bullying victimization on childhood mental health (Silberg et al. 2016), and suggesting that birth weight impacts the development of ADHD symptoms (Lim et al. 2018). Findings from the cotwin design can shed new light on the role of risk factors. For example, simple associations suggest that bullying victimization is a risk factor for most mental health outcomes over the long term, whereas twin differences designs point toward more specific effects (e.g., prominently on anxiety, depressive symptoms, and self-harm) and shorter-term effects (Singham et al. 2017). More elaborate longitudinal models can also be built based on twin differences. For example, a latent growth model has been implemented to show that differences in birth weight predict ADHD symptoms from childhood to adolescence, but that the size of the effect decreases with age, consistent with a partial "catch-up" effect (Lim et al. 2018). Cross-lag models can be implemented with twin differences to look at reciprocal influences between two phenotypes over time, while controlling for genetic and shared environmental confounding (Cecil et al. 2012).

\section{Comparing the Cotwin Control Design with the Classical Twin Decomposition}

The cotwin control design and the classical twin decomposition can be conceived as two approaches to decomposing a relationship: The former decomposes covariance among variables into within- and between-family effects, the latter into genetic, shared environmental and nonshared environmental components. In the majority of instances, when using twin samples for causal inference, these two methods are equivalent and should lead to the same conclusions. That is, when using the cotwin control design to focus on differences between MZ twins (within-family effects), researchers are in fact focusing on nonshared environmental variance (the $\mathrm{E}$ component in biometric twin models). When asking whether differences in $\mathrm{X}$ predict differences in $Y$, they are asking whether nonshared environmental variance in $\mathrm{X}$ predicts nonshared environmental variance in Y. Such statistical equivalence does not mean that one or the other method should be considered redundant. Twin decompositions will be of use to researchers interested in quantifying the relative effects of genetic, shared environmental and nonshared environmental correlations on covariance among variables. Conversely, cotwin control studies are not appropriate to examine the genetic architecture of traits; they have been used and are most useful for causal inference research as a particular implementation of fixed-effect models.

In the context of causal inference, both biometric decomposition and twin differences approaches suffer from the same two major limitations of unobserved, nonshared environmental confounders and the possibility of reverse causation. However, while twin differences and biometric decompositions are usually equivalent, there may be circumstances in which one design is appropriate and the other is not. For example, a version of the twin difference design has been applied to a sample of genotyped DZ twins to explore the extent to which differences in polygenic scores predicted differences in several early-life outcomes (Selzam et al. 2018, 2019). The intention was to control for the potential confounding effects of those influences shared within DZ twin pairs including population stratification, assortative mating, and indirect genetic effects from parents (genetic nurture). Genetic nurture occurs for example when genetic variants for education in the parents affect parental education, which in turn environmentally impacts child education. Such effects, although originating in the parental genotypes, are environmentally mediated and do not reflect direct genetic effects of the child genotype on the child phenotype (Eaves et al. 2014; Kong et al. 2018; Young et al. 2018; Hwang et al. 2020). Selzam et al. (2019) showed that twin differences in polygenic scores predicted differ- 
T.A. McAdams et al.

ences in height, body mass index (BMI), intelligence, educational achievement, and ADHD symptoms. However, the within-family prediction was attenuated for intelligence and educational attainment, indicating a degree of confounding. This finding required the use of a twin differences approach. A biometric decomposition would not be appropriate here as it would be inappropriate to treat polygenic scores as phenotypes (as any polygenic score would correlate 1 within $\mathrm{MZ}$ twins and 0.50 on average in DZ twins, resulting in A $=100 \%$, which would not capture and adjust for the genetic nurture effects).

\section{DIRECTION OF CAUSATION IN TWIN MODELS}

\section{Longitudinal Data}

In the models we have discussed thus far, the assumption has been that the direction of causation (DoC) runs from $\mathrm{X}$ to $\mathrm{Y}$ and not vice versa. However, often it is not possible to know with certainty whether this is the case. For example, in cross-sectional data, it may well be that $\mathrm{Y}$ causes $\mathrm{X}$ but it would not be possible using the models we have discussed to identify the true DoC. An often-used technique to identify the direction of effects is to use longitudinal data in which variables have a temporal order to them. For example, in a bivariate Cholesky decomposition, if $\mathrm{X}$ was measured before $\mathrm{Y}$, one could argue that the data should be modeled such that X predicts $\mathrm{Y}$ and not vice versa. That said, temporal ordering of measurement is often not justification enough to assume that a variable at time 1 should be modeled as a cause of a variable at time 2. For example, if school performance were measured at time 1 and IQ at time 2, the temporal ordering of measurement would not justify modeling the data based on the assumption that school performance causes IQ. Ideally, IQ and school performance would each be measured at time 1 and time 2, so that we can ask whether school performance prospectively predicts IQ after accounting for the correlation between IQ and school performance at time 1 and stability in IQ between time 1 and time 2 .
Autoregressive cross-lagged models are frequently used so that prospective associations among variables can control for the combined effects of contemporaneous associations among traits and across time stability within traits. For example, in Figure 4i, the prediction from X1 to $\mathrm{Y} 2$ controls for the effects of $\mathrm{Y} 1$ on $\mathrm{Y} 2$ and the covariance between $\mathrm{X} 1$ and $\mathrm{Y} 1$ (although see Hamaker et al. [2015] for a critique of some misperceptions regarding autoregressive crosslagged models and alternative specifications). A bivariate Cholesky decomposition of X1 predicting Y2 would potentially capture the confounding effects of Y1 through the genetic and shared environmental influences common to all but would not capture potential nonshared environmental confounders indexed by $\mathrm{Y} 1$.

Malanchini et al. (2017) present a biometric genetic version of the autoregressive crosslagged model in which four variables are decomposed into genetic, shared environmental and nonshared environmental components, and each of these components allowed to predict one another in the manner of an autoregressive cross-lagged simplex model (see Fig. 4ii-iv). In this model, the cross-lagged E predictions tell us whether, for example, X1 predicts Y2 after accounting for genetic and shared environmental influences common to these two variables and those influences-including nonshared environmental influences-shared with Y $1 .^{8}$ Malanchini et al. (2017) demonstrated the utility of this model by showing that although the phenotypic cross-lags between reading motivation and reading achievement in children were of equal magnitude, only the prediction from motivation to achievement survived correction for shared etiologies.

An alternative biometric autoregressive cross-lagged model to that presented here comprises a combination of the Cholesky decomposition and the correlated factors model (where,

\footnotetext{
${ }^{8}$ Note that this model is distinct to many other autoregressive cross-lagged twin models such as those critiqued by Luo et al (2010), in which correlations between X1 and Y1 and between the residual variances of $\mathrm{X} 2$ and $\mathrm{Y} 2$ are decomposed into A, C, and E components, but cross-lagged paths are not decomposed.
} 


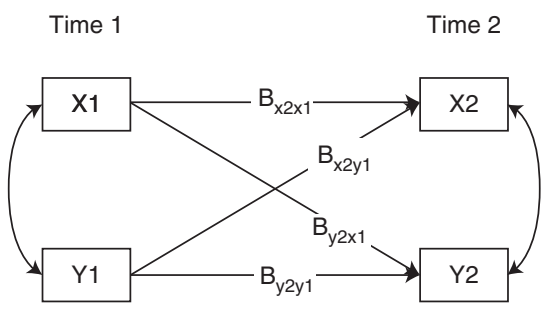

ii. Phenotypic autoregressive cross-lagged model

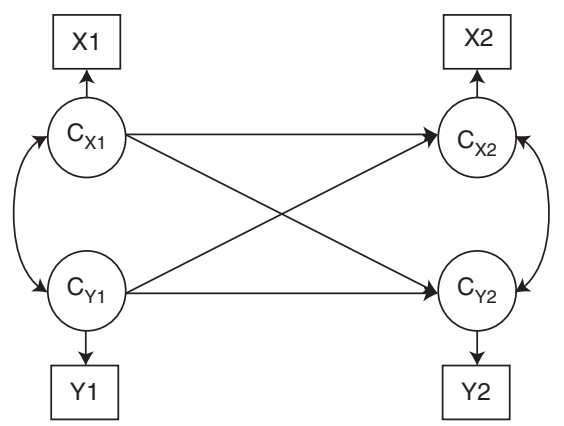

iii. ARCL model of shared environment influences

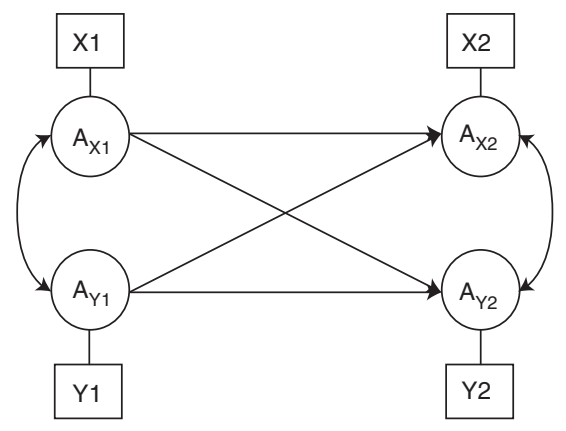

ii. ARCL model of genetic influences

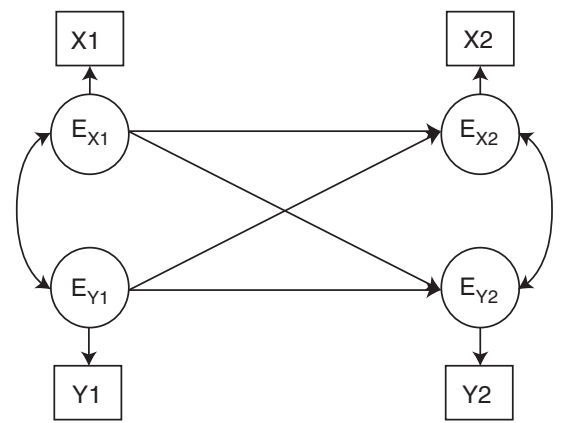

iv. ARCL model of nonshared environment influences

Figure 4. A phenotypic autoregressive cross-lagged model and partial path diagrams of a twin autoregressive cross-lagged model.

e.g., in Fig. 4ii, causal effects would run from $A_{x 1}$ and $A_{y 1}$ directly to $X 2$ and $Y 2$ rather than via $A_{x 2}$ and $A_{y 2}$; see Torvik et al. 2017, 2019). This model has been used to show that social anxiety disorder prospectively predicts alcohol use disorder-and not vice versa-after accounting for shared etiology (Torvik et al. 2019).

\section{Cross-Sectional Data and Direction of Causation Twin Models}

While longitudinal data is typically considered ideal for identifying the direction of effects, it is not always available. In such cases, cross-sectional twin data can, to some degree, help strengthen causal inference between two traits $\mathrm{X}$ and $\mathrm{Y}$. The DoC twin model (Heath et al. 1993; Duffy and Martin 1994) is distinct from most of the models described here in that the focus is not on controlling for the confounding effects of common etiologies. Rather it is on determining the likely direction of effects between two variables where temporal ordering is not present or is unknown (see Fig. 5i). That is, the extent to which an association between $\mathrm{X}$ and $\mathrm{Y}$ is driven by $\mathrm{X}$ predicting $\mathrm{Y}$ versus $\mathrm{Y}$ predicting $\mathrm{X}$. The power of this design is derived from the differential predictions that come about regarding the cross-twin, cross-trait correlations for MZ and DZ twin pairs when comparing the two potential causal models (X causes $\mathrm{Y}$ vs. $\mathrm{Y}$ causes $\mathrm{X}$ ). Differences in the covariance structure are predicted where the etiological structure (i.e., the relative importance of $\mathrm{A}, \mathrm{C}$, and $\mathrm{E}$ ) is distinct for trait $\mathrm{X}$ versus trait $\mathrm{Y}$. For example, where $\mathrm{A}$ affects trait $\mathrm{Y}$ but not $\mathrm{X}$, and $\mathrm{C}$ affects trait $\mathrm{X}$ but not $\mathrm{Y}$.

Figure 5 contains examples in which trait $\mathrm{X}$ is under the influence of $\mathrm{C}$ and $\mathrm{E}$, and trait $\mathrm{Y}$ is under the influence of $\mathrm{A}$ and $\mathrm{E}$. In 5ii, trait $\mathrm{X}$ causes $\mathrm{Y}$, and in 5iii, $\mathrm{Y}$ causes $\mathrm{X}$. If $\mathrm{X}$ causes $\mathrm{Y}$, 
T.A. McAdams et al.

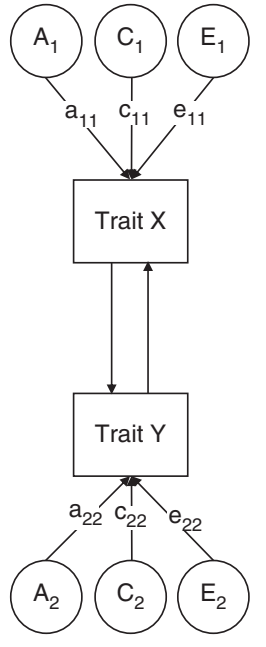

i. DoC partial path diagram

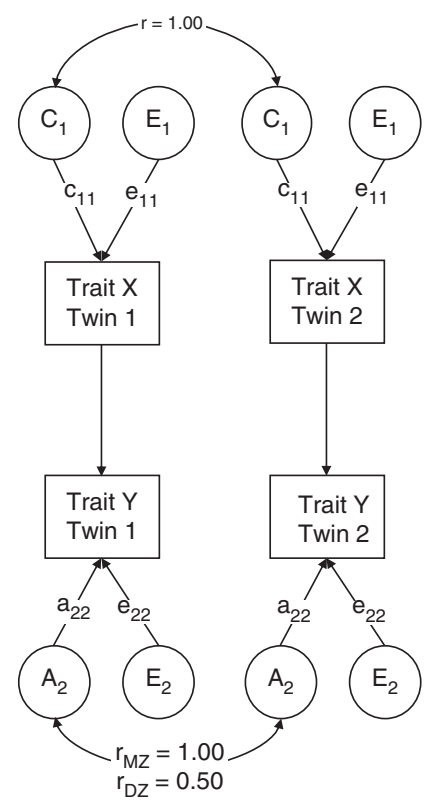

ii. DoC path diagram where $X$ causes $Y$

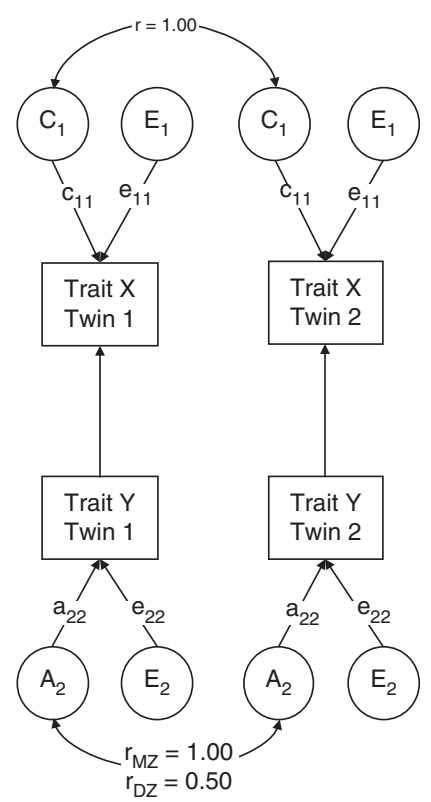

iii. DoC path diagram where $Y$ causes $X$

Figure 5. The direction of causation (DoC) twin model.

the expected cross-twin, cross-trait correlation (i.e., correlation between $\mathrm{X}$ in twin 1 and $\mathrm{Y}$ in twin 2, or $\mathrm{Y}$ in twin 1 and $\mathrm{X}$ in twin 2) can only be explained via the variance of variable $\mathrm{X}$. Because variable $\mathrm{X}$ is influenced by $\mathrm{C}$ and $\mathrm{E}$ only, the cross-twin, cross-trait correlations will be driven by $\mathrm{C}$. If $\mathrm{C}$ is the only thing that explains correlations between, for example, $\mathrm{X}$ in twin 1 and $\mathrm{Y}$ in twin 2, then these correlations will be the same for MZs and DZs (because C, the shared environment, by definition influences MZ and DZ twins equally). However, if $Y$ causes $X$, then the cross-twin, cross-trait correlations will be driven by variance in variable $Y$. Given that $Y$ in our example is under the influence of $\mathrm{A}$, the cross-twin, cross-trait correlations will be larger for MZs than DZs (Gillespie and Martin 2005). Whereas our example involves traits of very different etiologies, it is also possible to distinguish the direction of causation when the two traits have a similar but distinct etiology, for example, where trait $\mathrm{X}$ is under greater genetic influence than trait $Y$. In this manner, it has been shown that for the relationship between autism spectrum disorder and other mental health problems, best-fitting models suggest a unidirectional phenotypic influence of hyperactivity on identification of ASD. Relationships between ASD and emotional symptoms and conduct problems were best explained by correlated genetic and environmental factors, respectively (Tick et al. 2016).

A major assumption of the DoC model is that the association between $\mathrm{X}$ and $\mathrm{Y}$ is causal, that is, that it is not attributable to common causes unmodeled. In theory, it is possible to allow for correlations between etiological components of $\mathrm{X}$ and $\mathrm{Y}$ (i.e., between $\mathrm{A}_{1}$ and $\mathrm{A}_{2}$ or $\mathrm{C}_{1}$ and $\mathrm{C}_{2}$ ); however, doing so will reduce the ability of the model to distinguish the direction of effects. In practice, it is more usual for researchers to compare, for example, a Cholesky decomposition of $\mathrm{Y}$ on $\mathrm{X}$ with a DoC model and then select the model that provides the best fit to the data (e.g., Gillespie et al. 2012).

One way of thinking about the $\mathrm{DoC}$ model is that the variance components of one trait are being treated as instrumental variables in their prediction of the other trait. That is, their effects only operate through the causal effect of the 
intermediate trait. For example, $\mathrm{A}_{2}$ can only predict trait $\mathrm{X}$ through trait $\mathrm{Y}$. This is an assumption of the model and is analogous to the use of genetic variants and polygenic scores as instrumental variables in those methods collectively referred to under the umbrella term Mendelian randomization (Davey Smith and Ebrahim 2003; Smith and Ebrahim 2005; Davey Smith and Hemani 2014). Hwang et al. (2020) discuss extensions to the DoC model that incorporate Mendelian genetic tools to further strengthen the ability to draw causal inferences using this model. An alternative version of the DoC has also been suggested, in which the DoC between latent $\mathrm{C}$ and $\mathrm{E}$ factors (as opposed to among phenotypes) can be detected using datasets with non-normally distributed variables (Ozaki and Ando 2009).

\section{EXTENDED FAMILY DESIGNS}

Twin models make use of the fact that $\mathrm{MZ}$ and DZ twins differ in how genetically related they are to one another, and this information is used to infer how important genetic and environmental factors are in explaining variance in a trait and covariance among traits. However, the logic of the twin design is not confined to use in twin samples only. Indeed, it is possible to apply biometric ACE models to any datasets comprising differentially related relatives. For example, it is possible to use samples comprising siblings and half-siblings or cousins and halfcousins to estimate heritability and to explore the nature of covariance among phenotypes. ${ }^{9}$ Various extended family models have been proposed that make use of multigenerational data to examine the etiology of traits measured in two or more generations (Truett et al. 1994; Keller et al. 2009; Maes et al. 2009). Such models allow for the modeling of assortative mating, gene-envi-

\footnotetext{
${ }^{9}$ There are limitations to using such samples. For example, the lower relatedness coefficients will mean that statistical power is reduced relative to similarly sized samples of twin pairs. Where twins are always age-matched, siblings and cousins may not be, so appropriate controls/adjustments may need to be included in models where necessary. As sumptions regarding the definition of the "shared environment(s)" will also need to be made explicit.
}

ronment covariance, and other possibilities not feasible in a single-generation dataset. Extended family data also provides the opportunity for researchers to examine associations between family members. That is, they have the opportunity to ask questions about whether family members have an effect on one another, after accounting for their relatedness. For example, using data comprising twins and their children, it is possible to assess whether associations between parents and children persist after accounting for genetic relatedness (D'Onofrio et al. 2003; Silberg and Eaves 2004; McAdams et al. 2014).

\section{Children-of-Twins-and-Siblings Models}

Often, researchers are interested in the potential for parents to influence the development of their children. For example, associations between parenting behaviors and child behavioral and emotional traits are often interpreted in ways that imply that parenting causes child behavior (and/or vice versa). And intergenerational similarities in personality, psychopathology, and behavior are often interpreted as though exposure to a parent trait causes the development of the child trait. However, in most instances, parents and children are genetically related to one another and share an environment. As such, parent-child associations are likely to be at least partially attributable to the confounding effects of shared genetic and environmental influences.

Using samples comprising twins and their children, it is possible to decompose intergenerational associations into genetic and environmental components in much the same way that samples of twins can be used to decompose within-person associations. Where twin studies use differences in $\mathrm{MZ}$ and $\mathrm{DZ}$ cross-twin, crosstrait correlations, children-of-twin studies use differences in avuncular correlations (that between a twin and their cotwin's child/ren). As with twin data, children-of-twin data can be analyzed using a variety of models (Heath et al. 1985) and can be extended to include siblings (as well as twins) with children (Kuja-Halkola et al. 2014; Hannigan et al. 2018), multiple offspring per parent (McAdams et al. 2018), and 
T.A. McAdams et al.

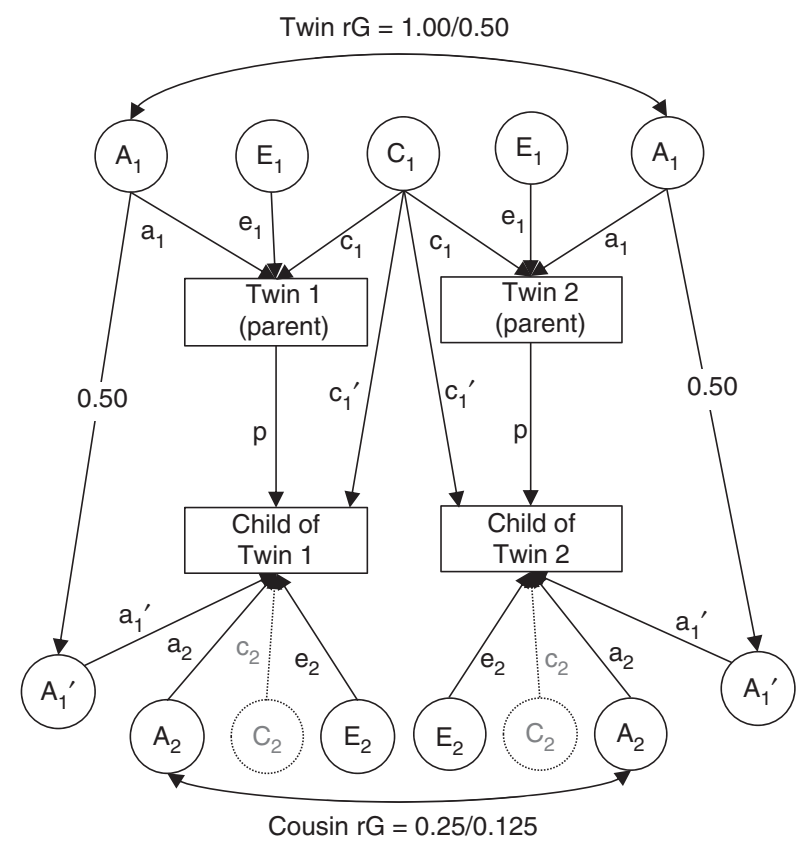

Figure 6. Children of twins structural equation model. $\left(a_{1}\right)$ Additive genetic effects on parental phenotype, $\left(c_{1}\right)$ shared environmental effects on parental phenotype, $\left(\mathrm{e}_{1}\right)$ nonshared environmental effects on parental phenotype, $\left(\mathrm{a}_{1}{ }^{\prime}\right)$ genetic effects common to parental phenotype and offspring phenotype, $\left(\mathrm{c}_{1}{ }^{\prime}\right)$ extended family environment effects on offspring phenotype, $\left(\mathrm{a}_{2}\right)$ genetic effects specific to offspring phenotype, $\left(\mathrm{c}_{2}\right)$ shared environmental effects on offspring phenotype (not estimable using cousin data), $\left(e_{2}\right)$ nonshared environmental effects on offspring phenotype, ( $p$ ) phenotypic effect of parent on offspring, (NB) the pathway between $A_{1}$ and $\mathrm{A}_{1}{ }^{\prime}$ is fixed to 0.50 because parents and children share $50 \%$ of their genome. To avoid overcomplicating path diagrams, variance paths have been omitted but for all latent factors, variance $=1$. For $\mathrm{A}_{1}{ }^{\prime}$ this means that residual variance (after accounting for the path between $\mathrm{A}_{1}$ and $\mathrm{A}_{1}{ }^{\prime}$ ) is 0.75 .

spouses (Silberg et al. 2010). In Figure 6, we show a simple version of a children-of-twins model comprising $\mathrm{MZ}$ and $\mathrm{DZ}$ twin pairs with one child per twin. In this model, both parent and child phenotypes are decomposed into genetic and environmental influences. In the child generation, this is possible by comparing cousins whose parents are MZ twins to those whose parents are $\mathrm{DZ}$ twins $(\mathrm{rG}=.25$ and .125 , respectively). If multiple children per twin are included, then siblings can be included in these estimations $(\mathrm{rG}=.50)$. Because cousins do not share a nuclear family environment, C (as typically defined) cannot be estimated in the offspring generation without the use of siblings. The intergenerational association between parent and child is decomposed into a genetic component $\left(\mathrm{A}_{1}{ }^{\prime}\right)$, an extended family component
$\left(\mathrm{C}_{1}{ }^{\prime}\right){ }^{10}$ and the remaining residual phenotypic association (p). If this "p" path predicts the child trait, then this indicates the association between parent and child phenotypes remains after accounting for shared genetic and environmental influences.

Models similar to that shown in Figure 6 have been used to examine a range of associations between parent and child traits, demonstrating, for example, that maternal depression during pregnancy does not predict later childhood emotional and behavioral problems after accounting for genetic confounding (Hannigan

\footnotetext{
${ }^{10}$ In extended family data, it is possible to model a range of different "shared environments." For example, maternal effects can be modeled in studies including maternal and paternal half siblings.
} 
et al. 2018), and that maternal smoking during pregnancy predicts birth weight and preterm birth but not cognitive abilities or externalizing behaviors in offspring after accounting for genetic confounds (Kuja-Halkola et al. 2014). Whereas most of these analyses are bivariate, these models are just as flexible as other twin models, so where appropriate data is available it will be possible, for example, to ask questions about the DoC between parent and child (Narusyte et al. 2008), longitudinal associations between parent and child, and gene-environment interplay.

\section{TWIN DATA AND EXPERIMENTAL DESIGN}

Thus far, we have discussed quasi-experimental research designs using samples of twin pairs. However, another (rarely employed) approach involves designing experiments using twin samples. Typically, experiments involve the random assignment of individuals to treatment and control conditions, with this random assignment intended to account for any confounders that might exist in a nonexperimental situation. Matched-pair designs go one step further and match pairs of subjects in the control and experimental conditions on any potentially important factors that might make pairs different from one another. Using twin data such that twin 1 receives a treatment and twin 2 does not provides an extreme example of this matched-pair design. Whereas twin 1 and 2 are members of an MZ pair, they will be matched on all genetic and shared environmental influences. Examples of this method include studies demonstrating how supplementation with vitamin $\mathrm{C}$ has no effect on self-reported incidences of the common cold (Carr et al. 1981; Martin et al. 1982).

An alternative take on the use of twins in experiments comes from a study by Haworth et al. (2016), in which they estimated changes in etiological influences on well-being and mental health in response to an online intervention delivered to all twins in a sample. They found that mean levels of well-being and mental health improved across the study, and that changes in well-being were accounted for by changes in nonshared environmental influences. However, while means changed and new nonshared environmental influences were evident postintervention, estimates of the relative importance of $\mathrm{A}, \mathrm{C}$, and $\mathrm{E}$ in explaining variance did not vary in magnitude pre- versus postintervention. These findings highlight a fundamental characteristic of biometric (ACE) twin models; such models focus on population variance in traits, not population means. Means can change without necessarily affecting the relative importance of genetic, shared environmental and nonshared environmental components.

\section{DISCUSSION}

In the preceding review, we have covered several ways in which twin data can be used by researchers interested in testing quasi-causal and causal hypotheses. As with all statistical models, those we have presented require careful and considered interpretation. In the following section, we explore some issues that we believe are important when attempting causal inference with twin data.

\section{Nonshared Environmental Confounds Are Not Accounted For}

Most of the models presented in this chapter are focused on controlling for genetic and shared environmental sources of confounding, and do not do anything to control for potential nonshared confounders. As such, the potential for nonshared environmental influences to confound associations should always be considered. For example, in an analysis in which smoking is the predictor, twins who smoke more than their cotwins may also drink more alcohol, such that alcohol rather than the putative risk factorsmoking-may be responsible for adverse outcomes. It is possible to statistically control for twin differences in covariates (e.g., alcohol consumption), but the models presented will still assume that there are no additional (unobserved) nonshared environmental confounders. To the extent that there are nonshared environmental confounders that are not accounted for, any residual association between predictor and outcome will be inflated. 
T.A. McAdams et al.

\section{Some Environments of Interest Do Not Differ between Twins}

It is worth noting that some environmental variables, such as childhood socioeconomic status (SES), or neighborhood characteristics during childhood, will not typically vary between twins. That is, where twins are reared by the same parents, in the same household, go to the same school, and live in the same neighborhood, they will not differ in terms of environmental measures related to parents, households, schools, and neighborhoods. This precludes the estimation of heritability of such variables using the twin design (i.e., MZ and DZ correlations will both be 1 in these cases). It also precludes the calculation of difference scores in the cotwin control design. Importantly, this does not necessarily mean that such variables are not under the influence of genetic factors, it is simply a limitation of the twin design that heritability cannot be estimated for variables that do not differ within twin pairs. As such, it is not possible to correct for etiological overlap involving such variables.

One solution to this problem lies in the use of intergenerational multiple-children-of-twinsand-siblings models. If a dataset comprises twins and siblings in the parent generation as well as the offspring generation (which would also then include cousins), it becomes possible to model the etiology of traits that can differ among siblings in the parent generation, such as, for example, parental SES. By modeling genetic and environmental relatedness between parents and children, it then becomes possible to account for genetic overlap between parent trait and child outcome. For example, this method has been used to demonstrate that parental educational attainment is predictive of child ADHD symptoms and academic problems at school, but not child depression symptoms, after accounting for genetic relatedness (Torvik et al. 2020).

\section{Statistical Power}

Much has been written about statistical power and twin studies (e.g., Visscher 2004; Verhulst 2017; Ahmadzadeh et al. 2020). In univariate studies, power to detect $\mathrm{A}$ (defined as twice the difference between $\mathrm{MZ}$ and $\mathrm{DZ}$ correlations) is contingent upon $\mathrm{MZ}$ and $\mathrm{DZ}$ correlations being significantly different from one another. Power to detect $\mathrm{C}$ is typically lower than that to detect $\mathrm{A}$, and relies on twins being more similar to one another than heritability accounts for. E will always be nonzero because it contains error variance.

When using bivariate and multivariate models as discussed in this article, the focus is on whether residual associations remain after accounting for potential genetic and shared environmental confounds. Whereas $\mathrm{E}$ (residual variance after accounting for $\mathrm{A}$ and $\mathrm{C}$ ) will always be nonzero in univariate models that explain variance in a single trait, this is not the case for covariance among traits, where residual covariance attributable to $\mathrm{E}$ can equal zero. As such, when decomposing covariance among traits for the purposes of causal inference, there should be two primary concerns relating to power:

1. How much power is there to detect genetic and shared environmental influences on the covariance?

2. If power to detect genetic and shared environmental influences on covariance is adequate, how large would the residual covariance need to be to be detected?

Where covariance among traits is low, or sample sizes are small, power to detect A or C influences on covariance will be low, and this may lead to incorrect conclusions being drawn regarding the significance and/or magnitude of residual covariance terms. Researchers should therefore be careful when interpreting residual covariance and consider how much power they have to detect confounding. Power calculations can be performed by simulating a dataset in which the sample composition, covariance, and proportions of covariance attributable to $\mathrm{A}, \mathrm{C}$, and the residual/E are known. By varying these proportions, researchers can evaluate the power they have in their own data (e.g., see Verhulst 2017 and associated website). 


\section{Measurement Error}

Measurement error is aggravated when computing difference scores, to the extent that traits are correlated within pairs. As a result, estimates from $\mathrm{MZ}$ differences may be attenuated compared to estimates in DZ differences, which themselves are attenuated compared to phenotypic estimates, even in the absence of confounding. This may lead to an underestimation of causal effects. Causal estimates can also be biased when the magnitude of measurement error is different for the risk factor and the outcome. This can be dealt with by directly modeling measurement error when possible, or by conducting a sensitivity analysis to estimate how much measurement error would be needed to substantially change the conclusions.

\section{The Importance of Context}

When using twin data to account for genetic or environmental overlap between two traits, one can think of the estimate of shared genetic influences as a "bivariate heritability" estimatean estimate of genetic influence on covariance (rather than variance). Like heritability estimates, these bivariate heritability estimates are population-specific and should not be assumed to necessarily generalize to other populations. Estimates of genetic and environmental influences on variance are known to vary with age (Haworth et al. 2010), across socioeconomic gradients (Tuvblad et al. 2006), and between countries (Hur 2008; Ball et al. 2009; Xu et al. 2015). In other words, contextual conditions have an effect on how much variance in a trait is explained by genetic and environmental variance in a population. This is also likely to be true for bivariate estimates and thus has implications for the use of twin data for the purposes of causal inference. If we find that the association between $\mathrm{X}$ and $\mathrm{Y}$ is entirely attributable to genetic overlap in our sample, this does not necessarily mean that the same will be true in other samples. Indeed, it may even be possible that the nature of the association varies within a sample. When this is deemed plausible, it is worth considering the inclusion of moderators in models where feasible. For example, it is conceivable that parental SES could moderate the nature of the association between maternal depression and child internalizing such that at high levels of SES (where social and economic resources are abundant), the association may be entirely genetic, but at low levels of SES (where support may be less available), there could be a causal effect of maternal depression on child internalizing. Where moderation is taking place but is not modeled, estimates regarding the association between $\mathrm{X}$ and $\mathrm{Y}$ will be biased.

\section{SUMMARY}

In this review, we have described some of the ways in which twin data can be used to interrogate causal hypotheses, particularly where experimental manipulation is not possible. The advantage of using twin and family data lies in the ability to control for latent genetic and shared environmental sources of potential confounding. This provides researchers with a powerful alternative to the often prohibitively challenging task of explicitly identifying and collecting data on potential confounds. We would argue that where an association of interest survives correction for the potential confounding effects of common genetic and shared environmental effects, then this should strengthen the argument for drawing causal inferences from the data (always bearing in mind the quasi-experimental nature of the design used). For example, if X predicts $Y$ after controlling for latent genetic and shared environmental effects that influence both variables, then it is possible that $\mathrm{X}$ causes $\mathrm{Y}$ and less likely that the association is attributable to common causes. If so, then interventions aimed at increasing or reducing $\mathrm{X}$ may have an effect on $\mathrm{Y}$. However, if the association between $\mathrm{X}$ and $\mathrm{Y}$ does not persist after controlling for latent genetic and shared environmental confounds, then it is unlikely that X causes $\mathrm{Y}$. It should therefore be considered less likely that intervening to alter $\mathrm{X}$ will also alter $\mathrm{Y}$.

In discussing the potential inherent in using twin and family data to interrogate causal hypotheses, we have highlighted some of the lim- 
T.A. McAdams et al.

itations, assumptions, and nuances that researchers should consider when doing so. It is worth noting, however, that many of these limitations are shared with other research methods and broadly relate to the generalizability of findings, and the importance of being cognizant of assumptions when interpreting results. Providing these issues are borne in mind, twin studies provide an extremely powerful tool for researchers interested in teasing apart potential causality from the effects of unknown confounders-a fundamental and central goal of all scientists concerned with the study of human beings.

For readers interested in using twin data for causal inference, a list detailing twin registries around the world, with links to detailed overviews of each, is published periodically in the journal Twin Research and Human Genetics (see Hur et al. 2020 for the most recent version).

\section{ACKNOWLEDGMENTS}

T.A.M. is supported by a Sir Henry Dale Fellowship, jointly funded by the Wellcome Trust and the Royal Society $(107706 / Z / 15 / Z)$. J.-B.P. is supported by an MQ Transforming Mental Health (MQ16IP16) award and the Medical Research Foundation 2018 Emerging Leaders 1st Prize in Adolescent Mental Health.

\section{REFERENCES}

${ }^{*}$ Reference is also in this collection.

Ahmadzadeh YI, Eley TC, Hannigan LJ, Creswell C, Lichtenstein P, Reiss D, Spotts E, Ganigan J, Neiderhiser JM, Rijsdijk FV, et al. 2020. Parental criticism and adolescent internalising symptoms: associations remain after accounting for shared genetic effects. medRxiv doi:10 $.1101 / 2020.05 .07 .20084319$

Ball HA, Sumathipala A, Siribaddana SH, Kovas Y, Glozier N, McGuffin P, Hotopf M. 2009. Genetic and environmental contributions to depression in Sri Lanka. $\mathrm{Br} J$ Psychiatry 195: 504-509. doi:10.1192/bjp.bp.109.063529

Carlin JB, Gurrin LC, Sterne JA, Morley R, Dwyer T. 2005. Regression models for twin studies: a critical review. Int $J$ Epidemiol 34: 1089-1099. doi:10.1093/ije/dyi153

Carr AB, Einstein R, Lai LY, Martin NG, Starmer GA. 1981. Vitamin $\mathrm{C}$ and the common cold using identical twins as controls. Med J Aust 2: 411-412. doi:10.5694/j.1326-5377 1981.tb101032.x

Cecil CA, Barker ED, Jaffee SR, Viding E. 2012. Association between maladaptive parenting and child self-control over time: cross-lagged study using a monozygotic twin difference design. Br J Psychiatry 201: 291-297. doi:10 .1192/bjp.bp.111.107581

Cheesman R, Eilertsen EM, Ahmadzadeh YI, Gjerde LC, Hannigan LJ, Havdahl A, Young AI, Eley TC, Rasmus Njolstad P, Magnus PM, et al. 2020. How important are parents in the development of child anxiety and depression? A genomic analysis of parent-offspring trios in the Norwegian Mother, Father and Child Cohort Study (MoBa). medRxiv doi:10.1101/2020.04.14.20064782

Conley D, Rauscher E, Dawes C, Magnusson PK, Siegal ML. 2013. Heritability and the equal environments assumption: evidence from multiple samples of misclassified twins. Behav Genet 43: 415-426. doi:10.1007/s10519013-9602-1

Davey Smith G, Ebrahim S. 2003. "Mendelian randomization": can genetic epidemiology contribute to understanding environmental determinants of disease? Int $J$ Epidemiol 32: 1-22. doi:10.1093/ije/dyg070

Davey Smith G, Hemani G. 2014. Mendelian randomization: genetic anchors for causal inference in epidemiological studies. Hum Mol Genet 23: R89-R98. doi:10.1093/ hmg/ddu328

D’Onofrio BM, Turkheimer EN, Eaves LJ, Corey LA, Berg K, Solaas MH, Emery RE. 2003. The role of the children of twins design in elucidating causal relations between parent characteristics and child outcomes. J Child Psychol Psychiatry Allied Disciplines 44: 1130-1144. doi:10 $.1111 / 1469-7610.00196$

Duffy DL, Martin NG. 1994. Inferring the direction of causation in cross-sectional twin data-theoretical and empirical considerations. Genet Epidemiol 11: 483-502. doi:10.1002/gepi.1370110606

Eaves LJ, Pourcain BS, Smith GD, York TP, Evans DM. 2014 Resolving the effects of maternal and offspring genotype on dyadic outcomes in genome wide complex trait analysis ("M-GCTA"). Behav Genet 44: 445-455. doi:10.1007/ s10519-014-9666-6

Fletcher JM. 2011. The promise and pitfalls of combining genetic and economic research. Health Econ 20: 889-892. doi:10.1002/hec.1745

Fletcher JM, Lehrer SF. 2011. Genetic lotteries within families. J Health Econ 30: 647-659. doi:10.1016/j.jhealeco .2011.04.005

Gage SH, Smith GD, Ware JJ, Flint J, Munafò MR. 2016. G = E: what GWAS can tell us about the environment. PLoS Genet 12: e1005765. doi:10.1371/journal.pgen.1005765

Gillespie NA, Martin NG. 2005. Direction of causation models. In Encyclopedia of statistics in behavioral science (ed. Everitt BS, Howell DC), Vol. 1, pp. 496-499. Wiley, Hoboken, NJ.

Gillespie NA, Gehrman P, Byrne EM, Kendler KS, Heath AC, Martin NG. 2012. Modeling the direction of causation between cross-sectional measures of disrupted sleep, anxiety and depression in a sample of male and female Australian twins. J Sleep Res 21: 675-683. doi:10.1111/j .1365-2869.2012.01026.x

Gjerde LC, Eilertsen EM, Hannigan LJ, Eley T, Røysamb E, Reichborn-Kjennerud T, Rijsdijk FV, McAdams TA, Ystrom E. 2019. Associations between maternal depressive symptoms and risk for offspring early-life psychopa- 
thology: the role of genetic and non-genetic mechanisms. Psychol Med 1-9. doi:10.1017/S0033291719003301

Hamaker EL, Kuiper RM, Grasman RP. 2015. A critique of the cross-lagged panel model. Psychol Methods 20: 102116. doi:10.1037/a0038889

Hannigan LJ, Eilertsen EM, Gjerde LC, Reichborn-Kjennerud T, Eley TC, Rijsdijk FV, Ystrom E, McAdams TA. 2018. Maternal prenatal depressive symptoms and risk for early-life psychopathology in offspring: genetic analyses in the Norwegian Mother and Child Birth Cohort Study. Lancet Psychiatry 5: 808-815. doi:10.1016/S2215-0366 (18)30225-6

Haworth CM, Wright MJ, Luciano M, Martin NG, de Geus EJ, van Beijsterveldt CEM, Bartels M, Posthuma D, Boomsma DI, Davis OSP, et al. 2010. The heritability of general cognitive ability increases linearly from childhood to young adulthood. Mol Psychiatry 15: 1112-1120. doi:10.1038/mp.2009.55

Haworth CM, Nelson SK, Layous K, Carter K, Bao KJ, Lyubomirsky S, Plomin R. 2016. Stability and change in genetic and environmental influences on well-being in response to an intervention. PLOS ONE 11: e0155538. doi:10.1371/journal.pone.0155538

Heath AC, Kendler KS, Eaves LJ, Markell D. 1985. The resolution of cultural and biological inheritance: informativeness of different relationships. Behav Genet 15: 439465. doi:10.1007/BF01066238

Heath AC, Kessler RC, Neale MC, Hewitt JK, Eaves LJ, Kendler KS. 1993. Testing hypotheses about direction of causation using cross-sectional family data. Behav Genet 23: 29-50. doi:10.1007/BF01067552

Hjelmborg J, Korhonen T, Holst K, Skytthe A, Pukkala E, Kutschke J, Harris JR, Mucci LA, Christensen K, Czene K, et al. 2017. Lung cancer, genetic predisposition and smoking: the Nordic Twin Study of Cancer. Thorax 72: 10211027. doi:10.1136/thoraxjnl-2015-207921

Hur YM. 2008. Sex differences in genetic and environmental contributions to depression symptoms in South Korean adolescent and young adult twins. Twin Res Hum Genet 11: 306-313. doi:10.1375/twin.11.3.306

Hur YM, Bogl LH, Ordoñana JR, Taylor J, Hart SA, Tuvblad C, Ystrom E, Dalgård C, Skytthe A, Willemsen G. 2020 Twin family registries worldwide: an important resource for scientific research. Twin Res Hum Genet 22: 427-437. doi:10.1017/thg.2019.121

* Hwang L-D, Davies NM, Warrington NM, Evans DM. 2020 Integrating family-based and Mendelian randomization designs. Cold Spring Harb Perspect Med doi:10.1101/ cshperspect.a039503

Jaffee SR, Price TS. 2007. Gene-environment correlations: a review of the evidence and implications for prevention of mental illness. Mol Psychiatry 12: 432-442. doi:10.1038/sj .mp.4001950

Keller MC, Medland SE, Duncan LE, Hatemi PK, Neale MC Maes HHM, Eaves LJ. 2009. Modeling extended twin family data I: description of the cascade model. Twin Res Hum Genet 12: 8-18. doi:10.1375/twin.12.1.8

Kendler KS, Baker JH. 2007. Genetic influences on measures of the environment: a systematic review. Psychol Med 37: 615-626. doi:10.1017/S0033291706009524

Kendler KS, Neale MC, Kessler RC, Heath AC, Eaves LJ. 1993. A test of the equal-environment assumption in twin studies of psychiatric illness. Behav Genet 23: 21-27. doi:10.1007/BF01067551

Kendler KS, Jacobson KC, Gardner CO, Gillespie N, Aggen SA, Prescott CA. 2007. Creating a social world: a developmental twin study of peer-group deviance. Arch Gen Psychiatry 64: 958-965. doi:10.1001/archpsyc.64.8.958

Kendler KS, Jacobson K, Myers J, Eaves L. 2008. A genetically informative developmental study of the relationship between conduct disorder and peer deviance in males. Psychol Med 38: 1001-1011. doi:10.1017/S003329170 7001821

Kong A, Thorleifsson G, Frigge ML, Vilhjalmsson BJ, Young AI, Thorgeirsson TE, Benonisdottir S, Oddsson A, Halldorsson BV, Masson G, et al. 2018. The nature of nurture: effects of parental genotypes. Science 359: 424-428. doi:10.1126/science.aan6877

Kuja-Halkola R, D'Onofrio BM, Larsson H, Lichtenstein P. 2014. Maternal smoking during pregnancy and adverse outcomes in offspring: genetic and environmental sources of covariance. Behav Genet 44: 456-467. doi:10.1007/ s10519-014-9668-4

Lim KX, Liu CY, Schoeler T, Cecil CA, Barker ED, Viding E, Greven CU, Pingault JB. 2018. The role of birth weight on the causal pathway to child and adolescent ADHD symptomatology: a population-based twin differences longitudinal design. J Child Psychol Psychiatry 59: 1036-1043. doi:10.1111/jcpp.12949

Luo YL, Haworth CM, Plomin R. 2010. A novel approach to genetic and environmental analysis of cross-lagged associations over time: the cross-lagged relationship between self-perceived abilities and school achievement is mediated by genes as well as the environment. Twin Res Hum Genet 13: 426-436. doi:10.1375/twin.13.5.426

* Lynch K. 2020. The meaning of "cause" in genetics. Cold Spring Harb Perspect Med doi: 10.1101/cshperspect .a040519

Maes HH, Neale MC, Medland SE, Keller MC, Martin NG, Heath AC, Eaves LJ. 2009. Flexible Mx specification of various extended twin kinship designs. Twin Res Hum Genet 12: 26-34. doi:10.1375/twin.12.1.26

Malanchini M, Wang Z, Voronin I, Schenker VJ, Plomin R, Petrill SA, Kovas Y. 2017. Reading self-perceived ability, enjoyment and achievement: a genetically informative study of their reciprocal links over time. Dev Psychol 53: 698-712. doi:10.1037/dev0000209

Martin N, Carr A, Oakeshott J, Clark P. 1982. Co-twin control studies: vitamin C and the common cold. Prog Clin Biol Res 103: 365-373.

McAdams TA, Gregory AM, Eley TC. 2013. Genes of experience: explaining the heritability of putative environmental variables through their association with behavioural and emotional traits. Behav Genet 43: 314-328. doi:10.1007/s10519-013-9591-0

McAdams TA, Neiderhiser JM, Rijsdijk FV, Narusyte J, Lichtenstein P, Eley TC. 2014. Accounting for genetic and environmental confounds in associations between parent and child characteristics: a systematic review of children-of-twins studies. Psychol Bull 140: 1138-1173. doi: $10.1037 / \mathrm{a} 0036416$.

McAdams TA, Hannigan LJ, Eilertsen EM, Gjerde LC, Ystrom E, Rijsdijk FV. 2018. Revisiting the children-oftwins design: improving existing models for the explora- 
T.A. McAdams et al.

tion of intergenerational associations. Behav Genet 48: 397-412. doi:10.1007/s10519-018-9912-4

Millwood IY, Walters RG, Mei XW, Guo Y, Yang L, Bian Z Bennett DA, Chen Y, Dong C, Hu R, et al. 2019. Conventional and genetic evidence on alcohol and vascular disease aetiology: a prospective study of 500,000 men and women in China. Lancet 393: 1831-1842. doi:10.1016/ S0140-6736(18)31772-0

Narusyte J, Neiderhiser JM, D'Onofrio BM, Reiss D, Spotts EL, Ganiban J, Lichtenstein P. 2008. Testing different types of genotype-environment correlation: an extended children-of-twins model. Dev Psychol 44: 1591-1603. doi:10.1037/a0013911

Neiderhiser JM, Reiss D, Pedersen NL, Lichtenstein P, Spotts EL, Hansson K, Cederblad M, Ellhammer O. 2004. Genetic and environmental influences on mothering of adolescents: a comparison of two samples. Dev Psychol 40: 335-351. doi:10.1037/0012-1649.40.3.335

Neiderhiser JM, Reiss D, Hetherington EM. 2007a. The Nonshared Environment in Adolescent Development (NEAD) Project: a longitudinal family study of twins and siblings from adolescence to young adulthood. Twin Res Hum Genet 10: 74-83. doi:10.1375/twin.10.1.74

Neiderhiser JM, Reiss D, Lichtenstein P, Spotts EL, Ganiban J. 2007b. Father-adolescent relationships and the role of genotype-environment correlation. J Fam Psychol 21: 560-571. doi:10.1037/0893-3200.21.4.560

Ozaki K, Ando J. 2009. Direction of causation between shared and non-shared environmental factors. Behav Genet 39: 321-336. doi:10.1007/s10519-009-9257-0

Pingault JB, O'reilly PF, Schoeler T, Ploubidis GB, Rijsdijk F, Dudbridge F. 2018. Using genetic data to strengthen causal inference in observational research. Nat Rev Genet 19: 566-580. doi:10.1038/s41576-018-0020-3

Plomin R, DeFries JC, Knopik VS, Neiderhiser JM. 2016. Top 10 replicated findings from behavioral genetics. Perspect Psychol Sci 11: 3-23. doi:10.1177/1745691615 617439

Polderman TJ, Benyamin B, De Leeuw CA, Sullivan PF, Van Bochoven A, Visscher PM, Posthuma D. 2015. Metaanalysis of the heritability of human traits based on fifty years of twin studies. Nat Genet 47: 702-709. doi:10.1038/ ng.3285

Rice F, van den Bree MBM, Thapar A. 2004. A populationbased study of anxiety as a precursor for depression in childhood and adolescence. BMC Psychiatry 4: 43. doi:10 .1186/1471-244X-4-43

* Richmond R. 2020. Mendelian randomization: concepts and scope. Cold Spring Harb Perspect Med doi: 10.1101/ cshperspect.a040501

Selzam S, McAdams TA, Coleman JR, Carnell S, O’Reilly PF, Plomin R, Llewellyn CH. 2018. Evidence for gene-environment correlation in child feeding: links between common genetic variation for BMI in children and parental feeding practices. PLoS Genet 14: e1007757. doi:10.1371/ journal.pgen.1007757

Selzam S, Ritchie SJ, Pingault J-B, Reynolds CA, O’Reilly PF, Plomin R. 2019. Comparing within- and between-family polygenic score prediction. Am J Hum Genet 105: 351363. doi:10.1016/j.ajhg.2019.06.006

Silberg JL, Eaves LJ. 2004. Analysing the contributions of genes and parent-child interaction to childhood behav- ioural and emotional problems: a model for the children of twins. Psychol Med 34: 347-356. doi:10.1017/ S0033291703008948

Silberg JL, Maes H, Eaves LJ. 2010. Genetic and environmental influences on the transmission of parental depression to children's depression and conduct disturbance: an extended children of twins study. J Child Psychol Psychiatry 51: 734-744. doi:10.1111/j.1469-7610.2010.02205.x

Silberg JL, Copeland W, Linker J, Moore AA, Roberson-Nay R, York TP. 2016. Psychiatric outcomes of bullying victimization: a study of discordant monozygotic twins. Psychol Med 46: 1875-1883. doi:10.1017/S00332917160 00362

Singham T, Viding E, Schoeler T, Arseneault L, Ronald A, Cecil CM, McCrory E, Rijsdijk F, Pingault JB. 2017. Concurrent and longitudinal contribution of exposure to bullying in childhood to mental health: the role of vulnerability and resilience. JAMA Psychiatry 74: 11121119. doi:10.1001/jamapsychiatry.2017.2678

Smith GD. 2011. Epidemiology, epigenetics and the "gloomy prospect": embracing randomness in population health research and practice. Int J Epidemiol 40: 537-562. doi:10.1093/ije/dyr117

Smith GD, Ebrahim S. 2005. What can mendelian randomisation tell us about modifiable behavioural and environmental exposures? BMJ 330: 1076-1079. doi:10.1136/bmj 330.7499.1076

Tick B, Colvert E, McEwen F, Stewart C, Woodhouse E, Gillan N, Hallett V, Lietz S, Garnett T, Simonoff E, et al. 2016. Autism spectrum disorders and other mental health problems: exploring etiological overlaps and phenotypic causal associations. J Am Acad Child Adolesc Psy chiatry 55: 106-113.e4. doi:10.1016/j.jaac.2015.11.013

Tikhodeyev ON, Shcherbakova OV. 2019. The problem of non-shared environment in behavioral genetics. Behav Genet 49: 259-269. doi:10.1007/s10519-019-09950-1

Torvik FA, Rosenström TH, Ystrom E, Tambs K, Røysamb E, Czajkowski N, Gillespie N, Knudsen GP, Kendler KS, Reichborn-Kjennerud T. 2017. Stability and change in etiological factors for alcohol use disorder and major depression. J Abnorm Psychol 126: 812-822. doi:10.1037/ abn0000280

Torvik FA, Rosenström TH, Gustavson K, Ystrom E, Kendler KS, Bramness JG, Czajkowski N, Reichborn-Kjennerud T. 2019. Explaining the association between anxiety disorders and alcohol use disorder: a twin study. Depress Anxiety 36: 522-532. doi:10.1002/da.22886

Torvik FA, Eilertsen EM, McAdams TA, Gustavson K, Zachrisson HD, Brandlistuen R, Gjerde LC, Havdahl A, Stoltenberg C, Ask H, et al. 2020. Mechanisms linking parental educational attainment with child ADHD, depression, and academic problems: a study of extended families in The Norwegian Mother, Father and Child Cohort Study. J Child Psychol Psychiatry doi:10.1111/jcpp.13197

Truett KR, Eaves LJ, Walters EE, Heath AC, Hewitt JK, Meyer JM, Silberg J, Neale MC, Martin NG, Kendler KS. 1994. A model system for analysis of family resemblance in extended kinships of twins. Behav Genet 24: 35 49. doi:10.1007/BF01067927

Turkheimer E, Harden KP. 2014. Behavior genetic research methods: testing quasi-causal hypotheses using multivariate twin data. In Handbook of research methods in social 
Twins and Causal Inference

and personality psychology (ed. Reis HT), pp. 159-187. Cambridge University Press, Cambridge.

Tuvblad C, Grann M, Lichtenstein P. 2006. Heritability for adolescent antisocial behavior differs with socioeconomic status: gene-environment interaction. J Child Psychol Psychiatry 47: 734-743. doi:10.1111/j.1469-7610 .2005.01552.x

Verhulst B. 2017. A power calculator for the classical twin design. Behav Genet 47: 255-261. doi:10.1007/s10519016-9828-9

Visscher PM. 2004. Power of the classical twin design revisited. Twin Res Hum Genet 7: 505-512. doi:10.1375/ 1369052042335250

Xu C, Sun J, Ji F, Tian X, Duan H, Zhai Y, Wang S, Pang Z, Zhang D, Zhao Z, et al. 2015. The genetic basis for cognitive ability, memory, and depression symptomatology in middle-aged and elderly Chinese twins. Twin Res Hum Genet 18: 79-85. doi:10.1017/thg.2014.76

Young AI, Frigge ML, Gudbjartsson DF, Thorleifsson G, Bjornsdottir G, Sulem P, Masson G, Thorsteinsdottir U, Stefansson K, Kong A. 2018. Relatedness disequilibrium regression estimates heritability without environmental bias. Nat Genet 50: 1304-1310. doi:10.1038/s41588018-0178-9

Young AI, Benonisdottir S, Przeworski M, Kong A. 2019. Deconstructing the sources of genotype-phenotype associations in humans. Science 365: 1396-1400. doi:10.1126/ science.aax 3710

Ystrom E, Eilertsen EM. 2019. Deconstructing the history of genotype-phenotype associations in humans. Science. Available at https://science.sciencemag.org/content/365/ 6460/1396/tab-e-letters 


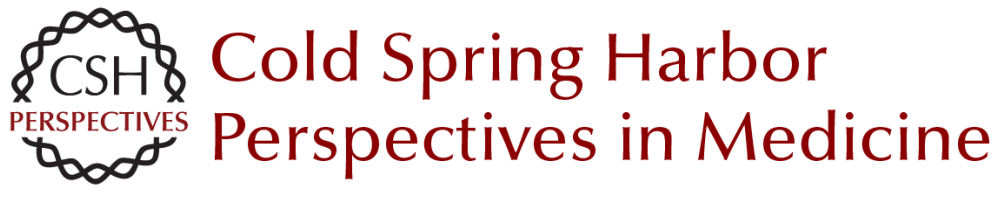

\section{Twins and Causal Inference: Leveraging Nature's Experiment}

Tom A. McAdams, Fruhling V. Rijsdijk, Helena M.S. Zavos and Jean-Baptiste Pingault

Cold Spring Harb Perspect Med 2021; doi: 10.1101/cshperspect.a039552 originally published online September 8, 2020

Subject Collection Combining Human Genetics and Causal Inference to Understand Human Disease and Development

Mendelian Randomization Ewan Birney

Human Genomics and Drug Development Amand F. Schmidt, Aroon D. Hingorani and Chris Finan

The Meaning of "Cause" in Genetics Kate E. Lynch

Using Mendelian Randomization to Improve the Design of Randomized Trials Brian A. Ference, Michael V. Holmes and George Davey Smith

Computational Tools for Causal Inference in Genetics

Tom G. Richardson, Jie Zheng and Tom R. Gaunt

Family-Based Designs that Disentangle Inherited Factors from Pre- and Postnatal Environmental Exposures: In Vitro Fertilization, Discordant Sibling Pairs, Maternal versus Paternal

Comparisons, and Adoption Designs Anita Thapar and Frances Rice

Polygenic Mendelian Randomization Frank Dudbridge
Causal Inference with Genetic Data: Past, Present, and Future Jean-Baptiste Pingault, Rebecca Richmond and George Davey Smith

Mendelian Randomization: Concepts and Scope Rebecca C. Richmond and George Davey Smith

Triangulating Evidence through the Inclusion of Genetically Informed Designs Marcus R. Munafò, Julian P.T. Higgins and George Davey Smith

Twins and Causal Inference: Leveraging Nature's Experiment Tom A. McAdams, Fruhling V. Rijsdijk, Helena M.S. Zavos, et al.

Integrating Family-Based and Mendelian Randomization Designs Liang-Dar Hwang, Neil M. Davies, Nicole M. Warrington, et al.

Causal Inference Methods to Integrate Omics and Complex Traits Eleonora Porcu, Jennifer Sjaarda, Kaido Lepik, et al.

\author{
Multivariable Mendelian Randomization and \\ Mediation \\ Eleanor Sanderson
}

For additional articles in this collection, see http://perspectivesinmedicine.cshlp.org/cgi/collection/ 